\title{
Educação e diversidades nas escolas do campo: a construção de práticas educativas interculturais
}

Elmo de Souza Lima*

Universidade Federal do Piauí

Resumo Os projetos educativos implementados nas escolas do campo fundamentam-se num pensamento pedagógico associado à racionalidade técnica, que privilegia um modelo de educação centrado na reprodução de conhecimentos e valores tidos como "verdades universais", vinculados às matrizes culturais "eurocêntricas" e "norte-americanas". As práticas educativas instituídas neste contexto trazem as marcas de uma pedagogia autoritária e colonizadora, na medida que, ignoram e/ou silenciam os saberes e as experiências culturais dos diversos povos que habitam este território e promovem a reprodução de conhecimentos deslocados daquele contexto sócio-histórico e cultural. Neste trabalho, buscamos refletir sobre as lutas dos movimentos sociais na defesa de um projeto de educação do campo, comprometido com a valorização das práticas sociais dos camponeses, à produção coletiva do conhecimento e a construção das alternativas de transformação social.

PALAVRAS-CHAVE: Educação do Campo; Interculturalidade;

Transformação social. 


\section{Education and diversities in the rural schools: the construction of educational intercultural practices}

Abstract The educational projects implemented in the rural schools are based on a pedagogical thinking associated to the technical rationality, which favors an educational model centered on the reproduction of knowledge and values considered to be "universal truths", linked to the "Eurocentric" and "North-American" cultural matrices. The educational practices instituted in this context show the presence of an authoritarian and colonizing pedagogy, in the means that they ignore and/or silence the knowledge and the cultural experiences of the various people who inhabit this territory, and promote the reproduction of knowledge that are displaced from that socio-historical and cultural context. In this work, we seek to reflect on the struggles of social movements in defense of a rural education project, commited to the valorization of rural people's social practices, to the collective production of knowledge and the construction of alternatives for social transformation.

KEYWORDS: Rural education; Interculturality; Social transformation.

Os diferentes estudos sociológicos e antropológicos desenvolvidos sobre a sociedade brasileira destacam as riquezas dessa nação associada ao encontro entre diferentes culturas, tais como: a ameríndia, a europeia e a africana. É uma nação que nasce sob a égide da diversidade e miscigenação cultural. No entanto, este encontro de povos e culturas nem sempre ocorreu de forma harmoniosa. Ao contrário disso, tivemos uma formação histórica marcada pela relação desigual entre povos de diferentes culturas, permeada pelas relações de poder/dominação, pelos encontros/conflitos, pelos enfrentamentos e estranhamentos contantes (LIMA, 2009).

Neste caso, a formação cultural da sociedade brasileira é marcada, por um lado, pela dominação cultural dos colonizadores portugueses sobre os povos colonizados e escravizados, no entanto, por outro lado, traz experiências significativas de hibridizações culturais como resultado dos processos de resistências, da construção de alternativas de diálogo e das experiências de convivência entre os diferentes povos.

No entanto, a lógica dominante no percurso da história política, social e cultural do Brasil está associada à relação desigual e de superioridade entre povos e culturas, com a supremacia da cultura europeia com relação aos outros povos. Assim, os saberes e as práticas socioculturais dos povos indígenas, africanos e seus descendentes sempre foram ignorados e/ou invisibilizados em nome de um padrão cultural considerando "moderno" e "civilizado".

Diante desse cenário, um conjunto de movimentos e organizações sociais surgiu em meio aos processos de lutas e resistências desses povos com o intuito de contraporem-se às injustiças sociais e às violências físicas, simbólicas e epistemológicas cometidas nos processos de imposição e dominação cultural. 
A partir da década de 1980, houve o fortalecimento destes movimentos sociais vinculados aos grupos sociais considerados "minoritários" (negros, indígenas, camponeses, quilombolas, mulheres, entre outros) colocando em cheque os padrões culturais e sociais utilizados historicamente pela sociedade e pelo Estado, de modo específico, na instituição das políticas públicas e na garantia dos direitos básicos às populações.

Para estes movimentos sociais, os modelos de desenvolvimento e as políticas públicas instituídas no Brasil a partir dos padrões socioculturais e ideológicos referenciados no pensamento eurocêntrico e norte-americano, não reconhecem as especificidades dos saberes, das tradições e das práticas sociais dos grupos "minoritários", pelo contrário, reforçam os mecanismos políticos e ideológicos de silenciamento, negação e invisibilização das tradições e dos conhecimentos e saberes das populações tradicionais (BRASIL, 2005).

Diante deste cenário, as lutas empreendidas pelos movimentos sociais, no final do século XX e na primeira década do século XXI, foram marcadas por avanços significativos no Brasil na afirmação dos direitos dos grupos sociais "minoritários" com a promulgação de diversas leis e diretrizes que vão tanto na direção do combate aos preconceitos étnico-raciais, religiosos, dentre outros, quanto na valorização e afirmação dos direitos e das práticas culturais das populações historicamentes excluídas, a exemplo dos povos do campo.

Desse modo, tivemos nas últimas décadas a constituição de vários programas e diretrizes voltadas à promoção da educação intercultural, a exemplo das Diretrizes Curriculares Nacionais para Educação Indígenas, em 1999; Diretrizes Operacionais para a Educação Básica nas Escolas do Campo, em 2002; Diretrizes Curriculares Nacionais para a Educação das Relações Étnico-raciais e para o Ensino de História e Cultura Afro-brasileira e Africana, em 2003; e as Diretrizes Curriculares Nacionais para a Educação Escolar Quilombola, em 2012; todas voltadas à promoção de práticas educativas que reconheçam as diversidades culturais e os diferentes saberes como forma de garantir a formação de cidadãos/ãs "capazes de interagir e de negociar objetivos comuns que garantam, a todos, respeito aos direitos legais e valorização de identidade, na busca da consolidação da democracia brasileira” (BRASIL, 2005).

Além disso, tivemos um conjunto de políticas públicas voltadas ao reconhecimento e à valorização dos grupos afro-brasileiros, indígenas, quilombolas, homossexuais, mulheres, entre outros, aspecto que não deixa de ser importante na construção de uma sociedade justa e democrática. Entretanto, são muitos os desafios que precisam ser superados com o intuito de consolidar estas políticas educacionais com a implementação de projetos educativos interculturais, que favoreçam a construção de uma cultura de respeito às diferenças e de convivência democrática em nosso país. 


\section{Notas sobre a emergência do pensamento intercultural no Brasil}

Os primeiros movimentos em defesa de uma educação que respeite as diversidades culturais no Brasil iniciaram no começo da década de 1960, com o desenvolvimento de projetos voltados à valorização e defesa da cultura popular instituídos pelos Centros Populares de Cultura (CPCs), o Movimento de Educação de Base (MEB) e pelo Movimento de Cultura Popular (MCP), inspirados nos ideais políticos e filosóficos do pensamento freireano.

$\mathrm{Na}$ visão de Freire (2005), a valorização da cultura popular era o caminho para o reconhecimento e afirmação das pessoas enquanto sujeitos históricos e o diálogo entre as diferentes culturas era estratégia para se ampliar a visão e compreensão destes sujeitos acerca do mundo, portanto, uma das alternativas para a emancipação das classes populares. Na perspectiva freireana,

[...] a cultura não é só a manifestação artística e intelectual que se expressa no pensamento. A cultura manifesta-se, sobretudo, nos gestos mais simples da vida cotidiana. Cultura é comer de modo diferente, é dar a mão de modo diferente, é relacionar-se com o outro de outro modo. A meu ver, a utilização destes três conceitos - cultura, diferenças, tolerância - é um modo novo de usar velhos conceitos. Cultura para nós, gosto de frisar, são todas as manifestações humanas, inclusive o cotidiano e é no cotidiano que se dá algo essencial: o descobrimento da diferença (FAUNDEZ; FREIRE, 1985, p. 34).

Em um contexto político e ideológico de negação e invisibilização das experiências políticas, organizativas e culturais das classes populares, Freire (2005) apostou numa proposta de educação libertadora comprometida com a valorização e a problematização da cultura popular. $\mathrm{Na}$ visão do autor, a educação emancipatória se constitui a partir da prática dialógica em que educadores/as e educandos/as estabelecem nas suas relações de convivência, de interação no/com mundo, bem como no modo de produzir-se na relação com os outros sujeitos e com o mundo.

Segundo Brandão (2002, p. 45), o projeto de educação popular instituído a partir do pensamento freireano e das práticas sociais e políticas dos movimentos dos anos 1960 foi um marco na luta contra a educação colonizadora implementada no Brasil, na medida em que reconheceram "na educação brasileira uma cultura alienada, produtora de sucessivas estruturas sociais de dominação e tradutora de sequentes esquemas simbólicos de valores, conhecimentos e princípios de relações sob controle de grupos e classes dominantes $[\ldots]$...

Nesta perspectiva, as experiências construídas pelos movimentos sociais na área da educação popular foram fundamentais na construção dos pilares da educação intercultural, na medida em que trouxeram para o campo da educação o debate político e epistemológico necessário ao desvelamento das relações de poder estabelecidas na sociedade brasileira a partir da dominação cultural. Para Oliveira (2011, p. 110),

No cenário do surgimento da educação popular no Brasil encontra-se a crítica dos movimentos populares à imposição da cultura 
dominante e a valorização de experiências da cultura popular, sendo realizado o debate epistemológico da legitimação social do saber popular, que historicamente é desvalorizado pelo seu corte de classe, gênero e etnia, em relação ao saber científico. A relação entre os saberes na educação popular está dimensionada no campo político e cultural.

Um aspecto relevante neste debate proposto por Freire (2005) e pelos movimentos em torno da educação popular, com relação à educação e à cultura popular, foi o deslocamento da discussão para o campo epistemológico, da legitimação social do conhecimento produzido pelas classes populares, frente ao processo de negação e silenciamento destes saberes em detrimento do conhecimento científico e dos padrões culturais impostos pelos projetos educativos e "civilizatórios" eurocêntricos.

O diálogo proposto por Freire (1986), entre educação e cultura, reafirmando que as práticas educativas precisam ser construídas em diálogo/interação constante com as práticas sociais, colocando-se enquanto espaço de trocas de experiências e vivências de novos e velhos conhecimentos, abre outras possibilidades de pensar a educação enquanto prática social, enquanto práxis, que funde e se reafirma enquanto prática cultural. Isto porque, para o autor,

Todos os produtos que resultam da atividade do homem [e das mulheres], todo o conjunto de suas obras, materiais ou espirituais, por serem produtos humanos que se desprendem do homem [e das mulheres], voltam-se para ele [ela] e o [a] marcam, impondo-lhe formas de ser e de se comportar também culturais. Sob este aspecto, evidentemente, a maneira de andar, de falar, de cumprimentar, de se vestir, os gestos são culturais. Cultural também é a visão que tem ou estão tendo os homens [e as mulheres] da sua própria cultura, da sua realidade (FREIRE, 1986, p. 57).

Neste processo, a cultura está associada à existência humana, ao processo de criação e recriação do mundo, implicado naquilo que dá sentido à vida dos sujeitos sociais e históricos. Desse modo, discutir processos educativos implicados com as práticas culturais dos sujeitos constitui-se numa condição essencial ao desenvolvimento de práticas educativas que, primeiro, tenham os sujeitos como protagonistas dos processos educativos e da produção do conhecimento; segundo, que tenha a capacidade de dialogar com os saberes e valores produzidos neste contexto, possibilitando uma maior apropriação desta experiência enquanto conhecimento crítico do seu fazer/agir no mundo, práxis social. Por fim, que assume o compromisso político de produzir conhecimento acerca da realidade como condição necessária ao processo de transformação social.

Neste debate sobre a relação entre a educação e a cultura, chama atenção a dimensão política proposta por Freire (2005) em suas reflexões sobre o tema. Se, por um lado, o autor denuncia o processo de dominação e violência simbólica instituído pela educação bancária e pelo processo de colonização cultural, através do silenciamento, invisibilização e negação da cultura, por outro, propõe o desenvolvimento de processos educativos que possam emergir do seio da cultura popular, tendo a realidade concreta como elemento central da produção do conhecimento e no processo de 
desvelamento da realidade, colocando o diálogo crítico sobre a cultura popular como condição para o processo de emancipação social.

Este debate também traz à tona o processo histórico de submissão e subalternização marcado por práticas culturais e políticas de desumanização e exclusão, que naturalizam as diferenças e ocultam as desigualdades. Neste caso, a educação libertadora concebida por Freire (2005), enquanto processo de humanização e prática da liberdade, traz em sua essência os pressupostos políticos e pedagógicos de uma educação intercultural, quando defende que:

Uma das tarefas mais importantes da prática educativo-crítica é propiciar as condições em que os educandos em relação uns com os outros e todos com o professor ou a professora ensaiam a experiência profunda de assumir-se. Assumir-se como ser social e histórico, como ser pensante, comunicante, transformador, criador, realizador de sonhos, capaz de ter raiva porque capaz de amar. Assumir-se como sujeito porque capaz de reconhecer-se como objeto. A assunção de nós mesmos não significa a exclusão dos outros. É a "outredade" do "não eu", ou do tu, que me faz assumir a radicalidade de meu eu (FREIRE, 1996, p. 23-24).

Por esta razão, o pensamento freireano trouxe contribuições relevantes para o debate da educação intercultural, principalmente com relação ao desenvolvimento de referenciais teórico-metodológicos voltados à proposição de projetos educativos que reconheçam os sujeitos sociais em suas especificidades, diferenças e peculiaridades, considerando este aspecto algo essencial na sua afirmação enquanto ser histórico e protagonista do processo de transformação social. Neste caso, é através do reconhecimento e valorização dos conhecimentos e experiências que os seres humanos construíram historicamente em suas vivências no/com o mundo, que teremos a capacidade de instituir processos formativos voltados ao empoderamento do/a educando/a, despertando-o/a para uma ação política transformadora.

Oliveira (2011) destaca um aspecto importante do pensamento freireano para o desenvolvimento de práticas educativas interculturais, relacionado à dimensão ética dos processos educativos, no que tange ao respeito e ao cuidado político e pedagógico que deve nortear os diálogos interculturais. É fundamental que seja instituído, nos processos educativos, um profundo respeito ao modo de pensar dos/as educandos/ as, aos seus conhecimentos e sua cultura, o que não significa ser conivente com visões ingênuas e/ou alienadas do mundo. Para Freire (1996, p. 16),

Pensar certo, do ponto de vista do professor, tanto implica o respeito ao senso comum no processo de sua necessária superação quanto o respeito e o estímulo à capacidade criadora do educando. [...] pensar certo coloca ao professor ou, mais amplamente, à escola, o dever de não só respeitar os saberes com que os educandos, sobretudo os das classes populares, chegam a ela - saberes socialmente construídos na prática comunitária - mas também, [...] discutir com os alunos a razão de ser de alguns desses saberes em relação com o ensino dos conteúdos. 
Nesta perspectiva, o autor traz dois elementos fundamentais para o debate sobre a educação intercultural; primeiro, evidencia o respeito ao/a educando/a, aos seus conhecimentos e saberes numa dimensão humanística, pautada na amorosidade que deve nutrir a relação entre educadores/as e educandos/as no processo de produção do conhecimento e reafirmação da vida; segundo, situa este debate no campo epistemológico, reconhecendo o significado político e cultural implícito no ato educativo de respeito e valorização dos "saberes da experiência" trazidos pelos/as educandos/as para o processo de produção do conhecimento no contexto das práticas educativas.

Ao propor este diálogo entre os diferentes saberes e práticas sociais, Freire (2005) institui uma lógica de pensar a produção do conhecimento pautada no diálogo, na complementaridade e interrelações entre conhecimentos e contextos, contrapondose aos processos de produção do conhecimento instituídos pelo pensamento científico moderno, fundado no princípio da descontextualização, fragmentação e neutralidade. Desse modo,

A interculturalidade em Paulo Freire tem como referência, não apenas a compreensão de que há diferenças entre as culturas e tensões entre elas, mas, sobretudo, a valorização das relações interculturais, que pressupõe a dialogicidade e a eticidade. Relações de respeito que se dimensionem como uma síntese cultural, viabilizando a dinâmica criadora do processo de produção cultural (OLIVEIRA, 2011, p. 122).

O pensamento pedagógico de Freire $(2005 ; 1996)$ foi importante para o desenvolvimento de inúmeras lutas políticas travadas por educadores e movimentos sociais na construção de políticas e práticas educativas comprometidas com a transformação social, a partir do reconhecimento e da valorização da diversidade cultural dos povos no Brasil.

\section{A contribuição dos movimentos sociais na construção de práticas educa- tivas interculturais}

De acordo com Boaventura Santos (2000), os movimentos sociais brasileiros e latino-americanos concentraram seus esforços, nas últimas décadas, na construção de estratégias teóricas e políticas pedagógicas capazes de contribuir na formação crítica dos sujeitos sociais historicamente excluídos nos vários confins brasileiros, silenciados pelo paradigma científico e cultural imposto pelos grupos hegemônicos, principalmente pelo modelo de ciência e conhecimento difundidos pelas academias e instituições de ensino.

Para o autor, os movimentos sociais latino-americanos desenvolveram não só estratégias políticas de enfrentamento aos processos de exclusão social, mas construíram alternativas epistemológicas que apontam na direção de outra forma de pensar o mundo, a partir do resgate e reconhecimento dos saberes e conhecimentos construídos historicamente pelos grupos afro-brasileiros, indígenas, quilombolas, camponeses, dentre outros. 
O trabalho dos movimentos sociais, por um lado, fomenta nos grupos sociais a capacidade de resistência e de reconhecimento da riqueza de suas tradições históricas negadas pelo pensamento hegemônico; por outro, desenvolve a capacidade crítica, organizativa e criativa para criar alternativas de resistência e de enfrentamento das lutas em defesa dos seus direitos, do reconhecimento dos seus saberes e suas diferentes formas de pensar e viver.

Os debates políticos construídos pelos movimentos sociais em torno das diferenças e diversidades socioculturais, políticas e organizativas, possibilitaram o reconhecimento destes grupos sociais como sujeitos históricos, com saberes e práticas sociais específicas e singulares, que assumem um papel essencial na construção das alternativas de desenvolvimento pautadas na sustentabilidade socioambiental, cultural, político e econômica frente às práticas excludentes do modelo capitalista.

As lutas políticas travadas pelos povos do campo pela garantia de direitos e afirmação de suas diferenças como condição essencial à vida numa sociedade democrática e justa contribuíram na construção de novos conhecimentos e articulações políticas, voltados ao desenvolvimento de novas leituras e reflexões acerca das relações de dominação instituídas a partir da cultura e da produção/legitimação do conhecimento.

Nessa perspectiva, os embates políticos e ideológicos ocorridos neste processo de afirmação e reconhecimento das diferenças/diversidades, contribuíram para o desvelamento das relações de dominação instituídas pelos grupos hegemônicos a partir dos interesses políticos e econômicos implícitos nos discursos e práticas da ciência moderna.

Para Santos (2000), este embate político ocorrido em torno do reconhecimento/afirmação dos saberes históricos e culturais, construídos pelos diferentes povos na sua relação com o mundo, nos seus processos históricos de produção da vida e de transformação da realidade, precisam ser deslocados e compreendidos dentro do campo epistemológico, compreendendo, portanto, a epistemologia enquanto "[...] campo da ciência que se ocupa dos métodos, da organização, da procedência, da validação e dos limites do conhecimento, bem como de sua relação com a realidade histórica - constitui-se em um espaço de relações de poder e, nesse sentido, de disputa" (STRECK; ADAMS, 2012, p. 247).

Por esta razão, Santos (2009) defende que este debate sobre as diversidades culturais seja desenvolvido a partir de outros referenciais epistemológicos capazes de se contraporem àqueles historicamente instituídos pela ciência clássica, que produz discursos científicos e culturais de subalternização epistêmica dos saberes, conhecimentos e interpretações do mundo divergentes dos modelos hegemônicos.

Numa perspectiva semelhante, Freire (2005) propôs uma teoria do conhecimento que se constituísse a partir do enraizamento histórico dos sujeitos e de sua inserção no mundo da cultura e das práticas sociais. Ou seja, invertendo a lógica epistêmica colonizadora, defendia que o conhecimento da realidade fosse construído a partir do pensar do próprio povo, de suas leituras e releituras do mundo. Um pensar que pudesse ser ampliado e criticizado na medida em que os sujeitos fossem capazes 
de estabelecer novos processos de problematização e reflexão crítica da realidade, instigados por meio de projetos educativos emancipadores.

A partir destes princípios políticos e epistemológicos de cunho emancipatórios, Santos (2009) defende que tenhamos a capacidade de conduzir este debate sobre a educação, a cultura e o conhecimento numa perspectiva ético-política, evidenciando o extermínio promovido pelo pensamento científico hegemônico com relação aos saberes, às culturas, experiências e práticas sociais dos povos minoritários.

Santos (2009) defende que, neste trabalho de reconhecimento e reafirmação das diversidades culturais, temos o dever ético de construir caminhos alternativos de resgate e afirmação dos diferentes conhecimentos e práticas sociais construídas historicamente pelos povos originários do sul, de modo que sua compreensão e relação com o mundo, seu paradigma de vida, fundado na justiça, solidariedade e respeito à diversidade sejam preservados e realimentados como possibilidade de construção de outro mundo possível.

$\mathrm{O}$ autor acrescenta ainda que estes conhecimentos construídos pelos povos originários, negados historicamente pelo pensamento científico hegemônico, trazem uma riqueza e um potencial enorme para este processo de transformação social, contrapondo-se aos projetos de desenvolvimento apresentados pela sociedade capitalista (SANTOS, 2009).

Diante desse contexto, os debates ocorridos dentro do Movimento de Educação do Campo estão associados à construção de estratégias políticas e pedagógicas que fomentem a apropriação crítica da realidade, em diálogo com os saberes construídos historicamente pelos povos do campo. Que a partir do diálogo crítico e das trocas de conhecimentos e experiências entre educandos e educadores, se busque produzir novos conhecimentos que ampliem o olhar acerca deste lugar, evidenciando novas possibilidades de pensar os modos de vida e convivência. Ou seja, trata-se de um trabalho que busca instituir uma disputa política e epistemológica no campo da interpretação das realidades (LIMA, 2015).

Neste debate, os movimentos sociais vêm reafirmando que os sujeitos do campo são diversos, portanto, as políticas de educação do campo e suas propostas curriculares precisam dialogar com suas especificidades sociais, culturais e organizativas, reconhecendo e valorizando as relações estabelecidas com o meio ambiente, o mundo do trabalho, nos rituais religiosos e nos processos de organização e produção da vida. São inúmeros os aspectos que reafirmam a diversidade dos povos do campo, a exemplo da sua relação com o mundo do trabalho (coletivo, cooperativo, individual, semicoletivo, assalariado, autônomo, mutirão etc.); na organização política (associações, movimentos organizados, sindicatos etc.); na organização social: festividades, atividades comunitárias, dentre outras. Nessa perspectiva, Caldart (2004, p. 153) alerta que:

O campo tem diferentes sujeitos. São pequenos agricultores, quilombolas, povos indígenas, pescadores, camponeses, assentados, reassentados, ribeirinhos, povos da floresta, caipiras, lavradores, roceiros, sem-terra, agregados, caboclos, meeiros, assalariados rurais e outros grupos mais. 
Este modo de pensar o campo em sua diversidade e especificidade traz outras preocupações com relação à complexidade dos processos sociais, culturais e educativos instituídos neste contexto, demandando, portanto, projetos educativos abertos ao diálogo e à troca de experiências e conhecimentos com estes povos, e suas organizações sociais, que compõem estes territórios rurais. Neste caso, precisamos compreender que:

Os povos do campo têm uma raiz cultural própria, um jeito de viver e de trabalhar, distinta do mundo urbano, e que inclui diferentes maneiras de ver e de se relacionar com o tempo, o espaço, o meio ambiente, bem como de viver e de organizar a família, a comunidade, o trabalho e a educação. Nos processos que produzem sua existência vão também se produzindo como seres humanos (ARROYO; CALDART; MOLINA, 2004, p. 16).

Com base nessa reflexão, os projetos educativos desenvolvidos nas escolas do campo precisam criar estratégias pedagógicas que favoreçam o diálogo entre os saberes diferentes e práticas, reconhecendo a importância das experiências dos camponeses para a consolidação do processo de luta e construção de uma sociedade democrática. Só teremos uma sociedade efetivamente democrática quando os vários grupos sociais forem reconhecidos enquanto produtores de saberes, tiverem seus direitos sociais garantidos e suas práticas sociais reconhecidas e incorporadas no contexto das experiências pedagógicas das escolas.

Na visão de Freire (1996), precisamos compreender, cada vez mais, a importância do diálogo entre as diferentes culturas como forma de tornar as práticas formativas mais ricas com relação à formação humana e crítica, transformando-as em espaços de possibilidade para a construção de sociedades democráticas, igualitárias e justas. Entretanto, os educadores precisam compreender que a construção dessas relações dialógicas entre os diferentes sujeitos nem sempre ocorre de forma pacífica, pois, para Freire (1992, p. 156), esse diálogo:

[...] não se constitui na justaposição de culturas, muito menos no poder exacerbado de uma sobre as outras, mas na liberdade conquistada, no direito assegurado de mover-se cada cultura no respeito uma da outra, correndo risco livremente de ser diferente, sem medo de ser diferente, de ser cada uma "para si", somente como se faz possível crescerem juntas e não experiência da tensão permanente, provocada pelo todo-poderosíssimo de uma sobre as demais, proibidas de ser.

A construção dessas práticas formativas, fundadas no princípio da dialogicidade, exige que os/as educadores/as estejam preparados, tanto no campo ético-político quanto no teórico-metodológico, para mediarem os conflitos e os embates que surgirão desses diálogos interculturais, possibilitando não a unificação das culturas e, muito menos, a negação de sua diversidade, mas a reafirmação de suas diferenças e a compreensão da importância dessa diversidade para a constituição de uma geração que respeite os diferentes modos de ser/estar no/com o mundo, engajando-se na defesa de uma sociedade pluricultural. Nessa perspectiva,

[...] a diversidade deve ser concebida como luta pelo direito de ser e como movimento de resistência às tentativas de homogeneização e 
enquadramento sociocultural de sujeitos tão diferentes, do ponto de vista da origem familiar e do capital cultural (BOURDIEU, 1998), e do ponto de vista econômico, que situa os sujeitos em determinada classe social, conforme seu capital econômico (MACHADO, 2010, p. 149).

Não podemos deixar de considerar que o debate sobre as diversidades precisa está associado às lutas contra as desigualdades e o processo de exclusão e negação de direitos à população do campo com relação ao acesso aos bens culturais produzidos pela humanidade. "A diversidade se coloca, então, no contexto da discussão sobre as desigualdade e marginalização daqueles que, historicamente, foram excluídos da sociedade" (MACHADO, 2010, p. 150).

O trabalho de valorização e reconhecimento das singularidades e especificidades dos povos do campo no contexto dos projetos educativos possibilita, por um lado, que a população camponesa compreenda que suas especificidades e diferenças culturais não os tornam inferiores aos demais grupos sociais, como historicamente foi propagado pelos discursos ideológicos eurocêntricos. Por outro, contribui no reconhecimento e autoafirmação de suas identidades sociais e culturais, bem como no fortalecimento de uma cultura contra-hegemônica, capaz de contrapor-se aos processos de dominação política e cultural instituídos no contexto da sociedade capitalista. Para Machado (2010, p. 151),

[...] o fortalecimento da cultura e da economia local pode revelar-se um poderoso instrumento de mudanças e de armação de uma nova ordem social. Contudo, isso não pode se dar com base em uma atitude romântica e ingênua de pensar que tudo se esgota/resolve em âmbito local, perdendo-se a dimensão do universal, do global.

A autora faz um alerta importante quanto aos riscos de nos limitarmos a pensar o local deslocando de uma leitura crítica mais ampla acerca dos processos de dominação política, ideológica e cultural imposta historicamente pelo sistema capitalista, numa perspectiva global. Assim, educandos/as e educadores/as precisam compreender que os processos históricos de opressão e exclusão vividos pelos povos do campo resultam da lógica perversa e injusta instituída pela ideologia capitalista. Compreender essa dimensão global do processo de exclusão é fundamental para se pensar em estratégias políticas articuladas contra as formas de dominação e opressão impostas à classe trabalhadora.

Machado (2010) alerta para outro aspecto fundamental, neste debate, sobre a educação e a interculturalidade, que está associado ao direito de os povos do campo terem acesso aos conhecimentos e à cultura universal produzida historicamente pela humanidade. Neste caso,

Coloca-se como primordial, então, a construção de propostas pedagógicas, que valorizem os diversos saberes dos sujeitos que vivem no campo, contudo, sem secundarizar o conhecimento científico e a cultura universal, que são fatores essenciais para a ampla formação dos sujeitos. Nesse processo, é fundamental incorporar a agroecologia como um novo conceito de vida, implicando não apenas uma produção mais saudável, livre de agrotóxicos, como também, a dis- 
cussão sobre soberania alimentar e manejo sustentável do solo e dos recursos naturais. Tais questões não se colocam apenas no plano técnico, mas fundamentalmente no plano das decisões políticas sobre o tipo de sociedade que queremos construir e sobre tipo de relações humanas que devem pautá-la (MACHADO, 2010, p. 146-147).

$\mathrm{O}$ fato de defendermos que as escolas precisam reconhecer e valorizar as diversidades socioculturais dos camponeses, bem como os saberes da experiência, não significa que iremos negar aos/as educandos/as o acesso aos conhecimentos científicos e a cultura universal. $\mathrm{O}$ acesso ao conhecimento sistematizado é condição essencial à superação das lógicas da dominação política e ideológica instituídas no campo, assim como à construção de novas perspectivas de desenvolvimento pautadas na sustentabilidade, que tenham a cultura e os saberes dos camponeses como instrumento de formação e mobilização social.

\section{O desenvolvimento de práticas educativas interculturais nas escolas do campo: desafios e possibilidades}

Os debates construídos em torno da educação e das diversidades culturais, associados às lutas políticas travadas pelos movimentos sociais para o reconhecimento do campo enquanto espaço de produção de conhecimento e saberes e dos camponeses como protagonistas de uma cultura perculiar aos seus modos de estar e atuar no/com o mundo, abriram novas possibilidades para se pensar as práticas educativas nas escolas do campo a partir de novos referenciais políticos e pedagógicos críticos, extrapolando aqueles modelos associados ao pensamento hegemônico, fundado no pensamento tecno-linear pautado nos ideais capitalistas/produtivistas americano.

Diante desse cenário, inúmeras experências estão sendo construídas nos vários cantos do país tendo as dinâmicas políticas e organizativas, bem como os rituais culturais das comunidades como matéria-prima para a produção desse novo fazer educativo que emerge da sabedoria popular, sem negar aos/as educandos/as o acesso ao conhecimento científico que passa a ser apropriado numa dinâmica de diálogo, interação e problematização com suas experiências socioculturais e políticas.

Neste caso, a produção do conhecimento se constitui no processo de reflexão crítica de suas próprias práticas sociais, no qual conhecer significa autoconhecer-se e apropriar-se de suas próprias histórias, a partir das releituras construídas no diálogo/ confronto com os conhecimentos construídos a partir de outros referenciais políticos e culturais. Assim, o conhecimento construído numa perspectiva intercultural possibilita não só a apropriação dos conceitos e concepções peculiares àquele conhecimento, mas implica a confrontação e reconstrução dos modos de pensar/estar no/com o mundo, produzindo novas posturas e atitudes críticas diante das diferentes possibilidades de compreender as relações sociais, políticas e econômicas que os diferentes grupos sociais estabelecem no mundo.

Nessa perspectiva, Fleuri (1999) defende a construção de projetos interculturais que fomentem o desenvolvimento de práticas educativas fundadas na "pedagogia do encontro" capaz de promover uma experiência profunda de encontro/confronto 
de narrações diferentes, oportunizando aos sujeitos a compreensão do mundo em sua diversidade e complexidade e a superação de preconceitos e estereótipos que impedem a construção de uma sociedade mais livre, justa e solidária. Assim,

[...] a educação intercultural se preocupa com as relações entre seres humanos culturalmente diferentes uns dos outros. Não apenas na busca de apreender o caráter de várias culturas, mas, sobretudo, na busca de compreender os sentidos que suas ações assumem no contexto de seus respectivos padrões culturais e na disponibilidade de se deixar interpelar pelos sentidos de tais ações e pelos significados constituídos por tais contextos [...]. Nesta óptica, o reconhecimento das complexas e conflitantes relações interculturais pode ser fundamental para reverter os processos de exclusão estabelecidos pela adoção de mecanismos culturais hegemônicos que perpassam a escola e transformam em estrangeiros muitos sujeitos sociais (FLEURI, 2003, p. 31).

O trabalho desenvolvido na área da educação intercultural traz como desafio a construção de outros modelos de educação abertos às diferentes formas de pensar as realidades locais, as práticas socioculturais, políticas e organizativas dos diferentes grupos sociais e, acima de tudo, reconhecer o valor e a relevância dos saberes produzidos nestes contextos. Neste debate, não podemos deixar de ter como foco central os princípios políticos e epistemológicos que norteiam as práticas formativas e de produção do conhecimento, tendo em vista que é a partir da compreensão destes e da desconstrução de determinados mitos epistemológicos podemos avançar na construção de práticas educativas interculturais.

Por esta razão, é importante desenvolver processos educativos e de pesquisa que sejam capazes de sistematizar princípios políticos e epistemológicos que deem conta de produzir referenciais teóricos e metodológicos capazes de apontar caminhos e/ou alternativas didático-pedagógicas voltados ao desenvolvimento de práticas educativas em que o diálogo entre os diferentes saberes e culturas possa ampliar a visão que os sujeitos têm de si e dos outros, numa relação de troca de saberes e práticas socioculturais.

Diante desse contexto, o investimento na formação de profisisonais da educação numa perspectiva intercultural é um dos caminhos estratégicos para consolidarmos o processo de democratização em curso na sociedade brasileira, com justiça social e a superação das práticas de exclusão no campo étnico, cultural, social, de gênero, de orientação sexual, de geração, dentre outras formas de negação de direitos instituídas historicamente nos modelos de desenvolvimento capitalista e neoliberal.

Para além disso, é fundamental reiventar os modelos pedagógicos que norteiam as práticas educativas no contexto das escolas do campo centrados numa pedagogia clássica voltada à transmissão acrítica de conteúdos, descontextualizados e sem uma vinculação com os contextos sociocultrais dos/as educandos/as, portanto, modelos educativos desenraizados culturalmente, associados aos projetos colonizadores fundados nos interesses políticos e pedagógicos norte-americanos e europeus. 


\section{As estratégias pedagógicas para o desenvolvimento de práticas educati- vas interculturais}

Os projetos educativos construídos na perspectiva intercultural precisam, num primeiro momento, oportunizar aos/as educandos/as tempos e espaços de pesquisas e estudos de seu próprio contexto sociocultural. É fundamental pensar em estratégias pedagógicas que favoreçam a inserção crítica das crianças e jovens no universo da cultura local como estratégias de reconhecimento das experiências e práticas sociais construídas historicamente pelo seu povo. O reconhecimento da história e da memória de sua comunidade é um caminho importante para o reconhecimento de si enquanto sujeito social que tem uma história coletiva que deve ser valorizada e visibilizada como forma de afirmar-se no mundo.

Nessa perspectiva, o resgate das histórias, das brincadeiras, das cantigas, dos rituais, dentre outros elementos da cultura camponesa, constituem-se em estratégias pedagógicas importantes para a reinserção das crianças e jovens no contexto histórico e cultural da comunidade, levando-os a redescobrirem os significados políticos e culturais presentes nestes elementos da cultura que dão vida às práticas sociais das pessoas. Compreender o significado dos elementos presentes na cultura do campo é um meio de manter viva esta cultura e a memória histórica desta gente.

O trabalho com os aspectos lúdicos da cultura camponesa pode ser uma estatégia pedagógica importante de instigar os/as educandos/as a adentrarem em questões mais complexas de estudos e pesquisas da realidade sociopolítica e cultural do campo. Os textos das músicas, das histórias e dos causos contados e cantados pelos camponeses estão permeados de aspectos históricos e políticos que podem transformar-se em teias e fios que se entrelaçam com os elementos sociais, políticos e econômicos da comunidade, desvelando cenários e paisagens pouco discutidas e refletidas pelas crianças e jovens no contexto da escola.

As próprias brincadeiras das crianças estão permeadas de elementos da vivência cotidiana que podem ser problematizados no sentido de fazê-las refletir sobre sua condição histórica no mundo, evidenciando as especificidades da vida do campo e as diferenças presentes entre os modos de ser/estar no mundo com aqueles vivenciados em outros territórios, destacando sigularidades, semelhanças, diferenças, riquezas e contradições implícitas nestes modos de viver nos diferentes contextos históricos e culturais.

De acordo com Brougère (1998, p. 103), o brincar é um elemento da cultura dotado de significações sociais que permitem compreender determinada sociedade. Desse modo, o brincar, como toda atividade cultural, é constituído por um sistema de significados e de interações simbólicas que possibilitam a imersão das crianças no mundo. Nesta perspectiva, o ato de brincar constitui um importante instrumento de reconhecimento e afirmação da cultura do campo, bem como de compreensão crítica de diferentes aspectos da realidade sociocultural e política do mundo rural.

Neste esforço de trazer à tona as histórias e as práticas sociais dos sujeitos do campo, é fundamental criar processos educativos de reconhecimento e valorização 
das diferenças culturais presentes neste contexto, superando o "daltonismo cultural" imposto pelos modelos hegemônicos de pensar a sociedade e as práticas culturais a partir de determinados padrões culturais (STOER; CORTESÃO, 1999).

Os processos educativos precisam evidenciar as riquezas culturais presentes no campo brasileiro e os diferentes modos de cultivar a terra, relacionar-se com a natureza, os diferentes meios de produção da vida, bem como os modos de organização social, as tradições culturais e folclóricas, de celebração da vida, entre outros. $\mathrm{O}$ reconhecimento desta diversidade no meio rural constitui-se num mecanismo de construção de um novo olhar sobre este território, para além dos estereótipos e visões preconceituosas, desvenlando um campo diverso, rico culturalmente e cheio de possibilidades de vida, no entanto, permeado por contradições e práticas de exclusão e negação de direitos sociais.

A construção de espaços e tempos nas escolas para os "relatos autobiográficos" e as "trocas de experiências" entre os/as educandos/as constitui uma estratégia interessante para se compreender como as diferenças socioculturais estão presentes no contexto do campo e como elas refletem no modo de ser/estar dos sujeitos no mundo. A partir das histórias de vida dos/as educando/as é possível construir leituras importantes sobre seu contexto histórico e cultural, utilizando-se dos conhecimentos das diferentes áreas do conhecimento, para se construir uma compreensão aprofundada acerca dos elementos sociais, políticos e culturais que estão implícitas nas experiências das famílias camponesas.

Desse modo, o estudo do contexto, a partir das histórias de vida, bem como de uma imersão programada de pesquisa sobre a realidade é possível estabelecer fecundas articulações entre as diferentes áreas do conhecimento, bem como instigar a confrontação entre estes saberes e práticas sociais, evidenciando as diversas concepções presentes nos modos de conhecer e compreender o mundo, implicadas em diferentes perspectivas políticas e ideológicas, refletidas também no modelo de desenvolvimento adotado no meio rural.

Do ponto de vista dos dispositivos didáticos, os projetos temáticos interdisciplinares, inspirados na pedagogia freireana, são os mais utilizados pelas escolas do campo com o propósito de aprofundar os estudos da realidade, bem como de produzir conhecimentos que favoreçam aos educandos/as uma inserção crítica nesta realidade, visando ao desenvolvimento de estratégias voltadas a melhoria da qualdiade de vida da população camponesa.

Neste trabalho com os projetos temáticos, os/as educandos/as assumem um papel de destaque na construção das alternativas de estudos e pesquisas, assim como, no processo de construção do conhecimento, favorecendo, por um lado, que as experiências e as leituras de mundo dos sujeitos do campo, construídas a partir da sua inserção/vivência nas lutas sociais, sejam reconhecidas e valorizadas no processo de investigação; por outro, que educandos/as sejam os protagonistas no processo de construção do conhecimento, assumindo o desafio de apresentar respostas e soluções para os problemas e as demandas sociais em questão. 
Desse modo, é importante que as estratégias políticas e pedagógicas utilizadas no desenvolvimento das práticas educativas implementadas nas escolas do campo possam, por um lado, superar os paradigmas hegemônicos de produção do conhecimento dissociados do contexto sociocultural do campo, permitindo que o ato de conhecer se constitua num processo rico de trocas de experiências e inserção crítica dos/as educando/as no mundo da cultura; por outro, que a compreensão do campo e das experiências históricas dos camponeses sejam compreendidas a partir de novos referenciais políticos e ideológicos, desmitificando leituras e concepções excludentes e preconceituosas acerca dos modos de vida do campo e de suas perspectivas de vida e desenvolvimento, pautadas na solidariedade e sustentabilidade.

\section{Considerações finais}

Se, por um lado, tivemos avanços significativos no âmbito da legislação educacional com a instituição de dispositivos legais que obriga o estado brasileiro a desenvolver políticas e projetos que fomentem o desenvolvimento de práticas educativas e curriculares voltadas à afirmação e ao reconhecimento das práticas sociais e culturais dos diferentes grupos sociais, colocando-os como protagonistas da construção do conhecimento nas escolas, por outro, temos o grande desafio de fazer com que estas conquistas possam ser materializadas nas centenas de escolas situadas no meio rural brasileiro.

O fato é que temos ainda uma estrutura de estado constituída a partir de determinados padrões culturais e científicos focada num pensamento hegemônico, que inviabiliza e/ou dificulta a concretização de inúmeras conquistas históricas dos movimentos sociais. Dentre os principais desafios, destaca-se a formação de novos profissionais da educação comprometidos com a implementação de políticas públicas que dialoguem com os saberes e as práticas socioculturais advindos do contexto das diversidades.

É importante ressaltar que as experiências formativas e profissionais dos/ as educadores/as e demais agentes públicos foram construídas, em grande medida, a partir dos referenciais políticos e epistemológicos que dão sustentação ao pensamento eurocêntrico e/ou norte-americano, que as impedem de reconhecerem as especificidades socioculturais.

Este cenário exige profundas mudanças no âmbito das políticas públicas, enquanto alternativa de garantia dos direitos socais e, de modo específico, do sistema educacional brasileiro, colocando novos desafios para as políticas educacionais, principalmente no campo da formação docente e na redefinição das políticas curriculares, pois, se por um lado, temos que democratizar as escolas e universalizar a educação básica, garantindo o acesso aos diferentes grupos sociais, por outro lado temos que pensar numa política de formação que prepare os profissionais da educação para acolher esses educandos em sua especificidade, complexidade e diferença, garantindo não só as condições da inclusão social, mas também a sua inserção enquanto sujeito no contexto sociopolítico e cultural brasileiro. 


\section{Referências}

ARROYO, Miguel. G.; CARDART, Roseli S.; MOLINA, Mônica. C. Por uma educação do campo. Petrópolis - RJ: Vozes, 2004

BORDIEU, Pierre. A escola conservadora: as desigualdades frente à escola e à cultura. In: NOGUEIRA, Maria Alice; CATANI, Afrânio M. (Org.). Escritos de educação. Petrópolis: Vozes, 1998.

BRANDÃO, Carlos Rodrigues. A educação como cultura. Campinas-SP: Mercado das Letras, 2002.

BRASIL. Secretaria de Educação Fundamental. Diretrizes Curriculares Nacionais para a Educação das Relações Étnico-Raciais e para o Ensino de História e Cultura Afro-Brasileira e Africana. Brasília: MEC; SEF, 2005.

BROUGERE, Gilles. A criança e a cultura lúdica. Revista da Faculdade de Educação, São Paulo, v. 24, n. 2, p. 103-116, Jul., 1998.

CALDART, R. S. Elementos para Construção do Projeto Político e Pedagógico da Educação do Campo. In: MOLINA, M. C; JESUS, S. M. Contribuições para a construção de um projeto de Educação do Campo. Brasília: Articulação Nacional por uma Educação do Campo, 2004

FLEURI, Reinaldo Matias. Educação intercultural no Brasil: a perspectiva epistemológica da complexidade. R. bras. Est. pedag., Brasília, v. 80, n. 195, p. 277-289, maio/ago. 1999.

FLEURI, Reinaldo Matias. Interculturalidade e educação. In: Revista Brasileira de Educação. São Paulo: n. 23, Maio/Jun/Ago, 2003.

FREIRE, Paulo. Pedagogia do oprimido. 17 ed. Rio de Janeiro: Paz \& Terra, 2005.

FREIRE, Paulo. Pedagogia da Autonomia. São Paulo: Paz e Terra, 1996.

FREIRE, Paulo; FAUNDEZ, A. Por uma Pedagogia da Pergunta. Rio de Janeiro: Paz e Terra, 1985.

FREIRE, Paulo. Educação e mudança. 11 ed. Rio de Janeiro: Paz e Terra, 1986.

LIMA, Elmo de S. Multiculturalismo, currículo e formação docente: construindo diálogos entre as diversidades no contexto das práticas educativas. Linguagens, Educação e Sociedade, Teresina, Ano14, n. 21, p. 15-31, Jul/Dez. 2009.

LIMA, Elmo de S. Formação continuada de educadores/as: as possibilidades de reorientação do currículo. Curitiba: CRV, 2015.

MACHADO, Ilma Ferreira. Educação do campo e diversidade. Perspectiva, Florianópolis, v. 28, n. 1, 141-156, Jan./Jun. 2010.

OLIVEIRA, Ivanilde A. de. Cultura e interculturalidade na educação popular de Paulo Freire. EccoS Revista Científica, São Paulo, nº. 25, p. 109-124, Jan./Jun., 2011.

SANTOS, Boaventura de Sousa. A crítica da razão indolente: contra o desperdício da experiência. São Paulo: Cortez, 2000.

SANTOS, Boaventura de Sousa; Para além do Pensamento Abissal: das linhas globais a uma ecologia de Saberes. In: SANTOS, Boaventura de S.; MENESES, Maria P. (Orgs.) Epistemologias do Sul. São Paulo: Cortez, 2009.

STOER, Stephen; CORTESÃO, Luiza. Levantando a Pedra da Pedagogia Inter/multicultural às Políticas Educativas numa época de Transnacionalização. Porto: Ed. Afrontamento, 1999.

STRECK, Danilo Romeu; ADAMS, Telmo. Pesquisa em educação: os movimentos sociais e a reconstrução epistemológica num contexto de colonialidade. Educação e Pesquisa, São Paulo, v. 38, n. 1, p. 243-257, 2012. 
* Doutor em Educação, professor do Programa de Pós-graduação em Educação (PPGEd) da Universidade Federal do Piauí, Teresina, Piauí, Brasil..

\section{Correspondência}

Elmo de Souza Lima - Universidade Federal do Piauí, Centro de Ciências da Educação, Programa de Pós-Graduação em Educação - UFPI. Campus Universitário Ministro Petrônio Portella, Ininga. CEP: 64049550. Teresina, Piauí, Brasil.

E-mail: elmolima@gmail.com

Recebido em 01 de setembro de 2017

Aprovado em 08 de maio de 2018 